\title{
Plateau Iris, a diagnostic challenge. Case report
}

\section{Iris plateau, reto diagnóstico. Reporte de caso}

\author{
Dora A. Ochoa-Araujo*, Judith S. Sarmina, and Deyanira P. Zapata-Susanivar
}

Ophthalmology department, Hospital Regional Lic. Adolfo López Mateos, Instituto de Seguridad y Servicios Sociales de los Trabajadores del Estado, Mexico City, Mexico

\begin{abstract}
Introduction: Plateau iris is an anatomical change that consists on the absence of the ciliary sulcus and the presence of anteriorly positioned ciliary processes that push the root of the iris at the level of its insertion. Case report: $A$ 74-year-old female was sent to our center with a diagnosis of primary angle-closure glaucoma. After an initial assessment, we decided to perform an iridotomy, observing favorable angle changes initially and then an angle closure, so a ultrabiomicroscopy was performed that allowed to diagnose plateau iris in both eyes. Discussion: The diagnosis of plateau iris should be suspected when there is a persistent angle closure even with permeable iridotomies and partial opening of the angle. Conclusion: This case is relevant because the low incidence of plateau iris can lead to underdiagnosis.
\end{abstract}

Key words: Primary angle-closure glaucoma. Plateau iris. Diagnosis. Treatment.

\section{Resumen}

Introducción: El iris plateau es un cambio anatómico que consiste en la ausencia del surco ciliar y la presencia de procesos ciliares anteriores que empujan la raíz del iris a nivel de su inserción. Caso clínico: Mujer de 74 años enviada a nuestro centro con diagnóstico de glaucoma primario de ángulo cerrado. Tras la valoración inicial se decidió realizar iridotomía, encontrando cambios angulares favorables de inicio y posteriormente cierre angular, por lo que se realizó ultrabiomicroscopia y se halló iris plateau en ambos ojos. Discusión: Se debe sospechar el diagnóstico de iris plateau cuando existe cierre angular persistente incluso con iridotomías permeables y apertura parcial del ángulo. Conclusión: El caso presentado es relevante debido a que la baja incidencia de iris plateau nos puede llevar a infradiagnosticarlo.

Palabras clave: Glaucoma primario de ángulo cerrado. Iris plateau. Diagnóstico. Tratamiento.

\section{Introduction}

The plateau iris configuration is defined as an anatomical change that consists on the absence of ciliary sulcus and the presence of anteriorly situated ciliary processes that push the periphery of the iris, causing an anterior angulation of the peripheral iris in its insertion and a central angulation ${ }^{1}$. The surface of the iris is relatively flat, giving the appearance of a plateau in a sagittal section. Plateau iris syndrome is defined as a persistently narrow angle capable of closure despite a patent peripheral iridotomy ${ }^{1,2}$.

\section{Correspondencia:}

*Dora A. Ochoa-Araujo

Av. Universidad, 1321

Col. Axotla

Fecha de recepción: 13-07-2019

Fecha de aceptación: 25-04-2020

C.P. 01030, Ciudad de México, México

E-mail: alineochoaa @gmail.com

DOI: 10.24875/RMOE.M21000167

2604-1731/๑ 2020 Sociedad Mexicana de Oftalmología. Published by Permanyer. This is an open access article under the CC BY-NC-ND license (http://creativecommons.org/licenses/by-nc-nd/4.0/). 
Plateau iris syndrome can be complete, when the angle is closed to the upper trabecular meshwork or the Schwalbe line and intraocular pressure (IOP) is increased due to aqueous outflow blocking, or incomplete, when the angle is partially closed and the upper trabecular meshwork remains open, allowing drainage of aqueous humor so that the IOP remains at normal values ${ }^{3,4}$.

Plateau iris represents $10 \%$ of cases of primary angle closure and is one of the less frequent causes of angle-closure glaucoma. It is more common in women before the age of $50^{3-5}$.

\section{Clinical case}

A 74-year-old woman, resident of Mexico City, with a 20-year history of diabetes mellitus treated with NPH insulin (17 units) and systemic arterial hypertension treated with enalapril $10 \mathrm{mg}$ (1 tablet every 24 hours). The patient denied smoking and drinking, as well as other non-pathological history. Regarding ocular history, she had a diagnosis of angle-closure glaucoma in December 2017 (in a secondary care center), treated with timolol/brimonidine $0.5 \% / 0.2 \%$ (1 drop every 12 hours in both eyes), which was instilled occasionally with no actual adherence to treatment. There was no another non-pathological history. She was referred to the Hospital Regional Lic. Adolfo López Mateos (Instituto de Seguridad y Servicios Sociales de los Trabajadores del Estado), to the glaucoma service, to evaluate the need of an iridotomy in both eyes.

During her first evaluation in our hospital, we found a visual acuity in the right eye of $20 / 50$, with a visual capacity of $20 / 25$, refraction $+1.50=-2.50 \times 95^{\circ}$; left eye with a visual acuity of $20 / 60$ and a visual capacity of $20 / 30$, refraction $+1.00=-0.75 \times 50^{\circ}$. Intraocular pressure in the right eye was of $17 \mathrm{mmHg}$ and in the left eye of $23 \mathrm{mmHg}$. Biomicroscopy of the right eye showed a clear cornea, formed anterior chamber with a narrow periphery and wide in the center, regular iris, reactive pupil, preserved pupillary reflexes, lens with a LOCS III NO2NC2C2P0 opacity; the left eye with a clear cornea, formed anterior chamber with a narrow periphery and wide in the center, regular iris, reactive pupil, preserved pupillary reflexes, lens with a LOCS III NO2NC2C2P0 opacity. Gonioscopy revealedaconvexiris in both eyes. Right eye SHAFFER II in lower, upper and nasal quadrants, SHAFFER III in temporal quadrant. Left eye SHAFFER II in all four quadrants. Fundscopy showed in the right eye a clear vitreous, orange optic disc with a 0.65 cup-to-disc ratio with a nasal shifting of disc vessels, applied retina and macula, choroidal fundus; in the left eye, clear vitreous, orange optic disc with a 0.70 cup-to-disc ratio with a nasal shifting of disc vessels, applied retina and macula, choroidal fundus.

Given these signs and symptoms, a diagnosis of primary angle-closure glaucoma was made.

We decided to perform YAG-laser iridotomy only in the left eye, since the right eye had an open-angle quadrant. Twenty-four hours after the procedure we observed a patent iridotomy with an IOP of $25 \mathrm{mmHg}$ and iridocorneal angles unchanged. Five days after the iridotomy, the patient had an IOP of $19 \mathrm{mmHg}$, with changes by gonioscopy of the lower and temporal quadrants to SHAFFER III, while the upper and nasal quadrants remained in SHAFFER II. On her third visit, 14 days later, she had an IOP of $19 \mathrm{mmHg}$, with a change by gonioscopy back to SHAFFER II in all four quadrants, so we decided to perform an anterior segment optical coherence tomography (OCT) of both eyes looking for a potential plateau iris. The findings revealed a patent iridotomy with a narrow angle and an image compatible with a double hump.

A diagnosis of probable plateau iris configuration in the right eye and probable plateau iris syndrome in the left eye was suspected, so an ultrabiomicroscopy (UBM) of the anterior segment was requested that corroborated the diagnosis of plateau iris in both eyes (Fig. 1).

We decided to perform a comprehensive evaluation of the patient, requesting visual fields (standard automated static perimetry 24-2 SITA type with a reliable stimulus size III). A mean deviation of -5.90 decibels was observed in the right eye, with a slight blind spot enlargement and upper nasal step increase, unlike the left eye, which presented a mean deviation of -11.64 decibels and a blind spot enlargement with a superior arcuate scotoma (Fig. 2).

By OCT of the optic nerve, both eyes showed an increased vertical cup-disc ratio and a decrease of the lower retinal nerve fiber layer thickness. This correlated with the findings in the aforementioned visual fields.

With the definitive diagnosis, it was decided to perform argon laser peripheral iridoplasty in both eyes (Fig. 3). Four weeks after iridoplasty, the IOP in the right eye was $10 \mathrm{mmHg}$ and in the left eye $11 \mathrm{mmHg}$, with favorable changes by gonioscopy showing SHAFFER IV angles in the four quadrants of both eyes (Fig. 4). It is worth mentioning that from the first evaluation the patient was instructed to adhere to the timolol/brimonidine $0.5 \% / 0.2 \%$ treatment, 1 drop every 12 hours in both eyes.

\section{Discussion}

Plateau iris is one of the least thought causes of angle-closure glaucoma. It is more common in women 


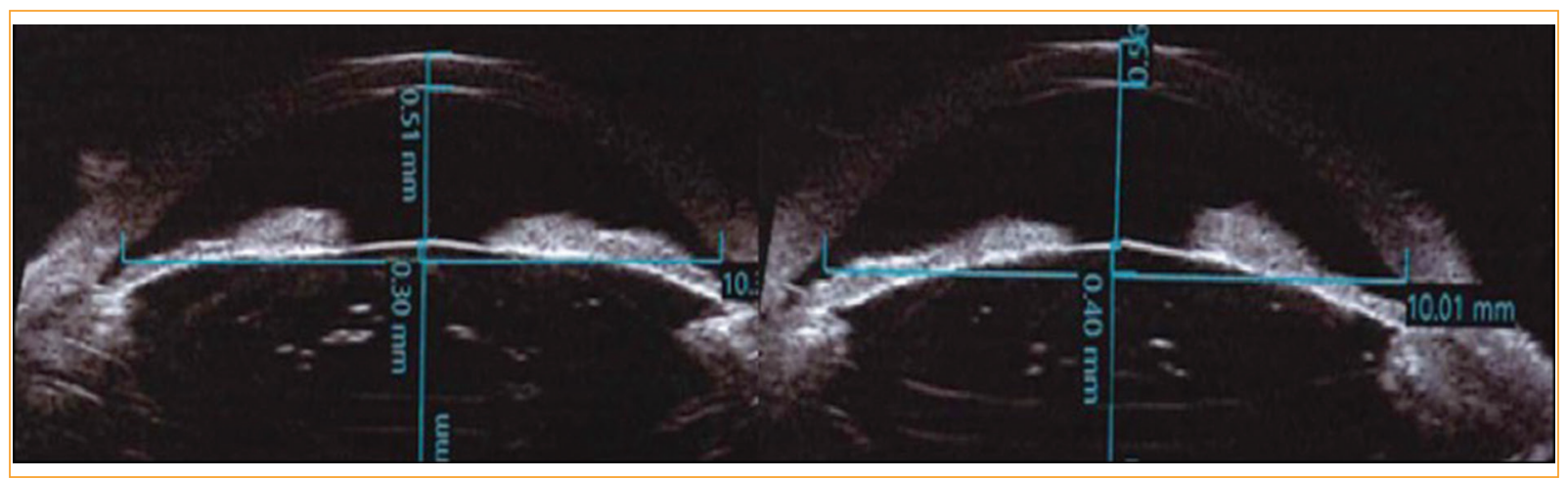

Figure 1. Ultrabiomicroscopy of the right eye and the left eye showing absence of ciliary sulcus and anteriorly situated ciliary processes.

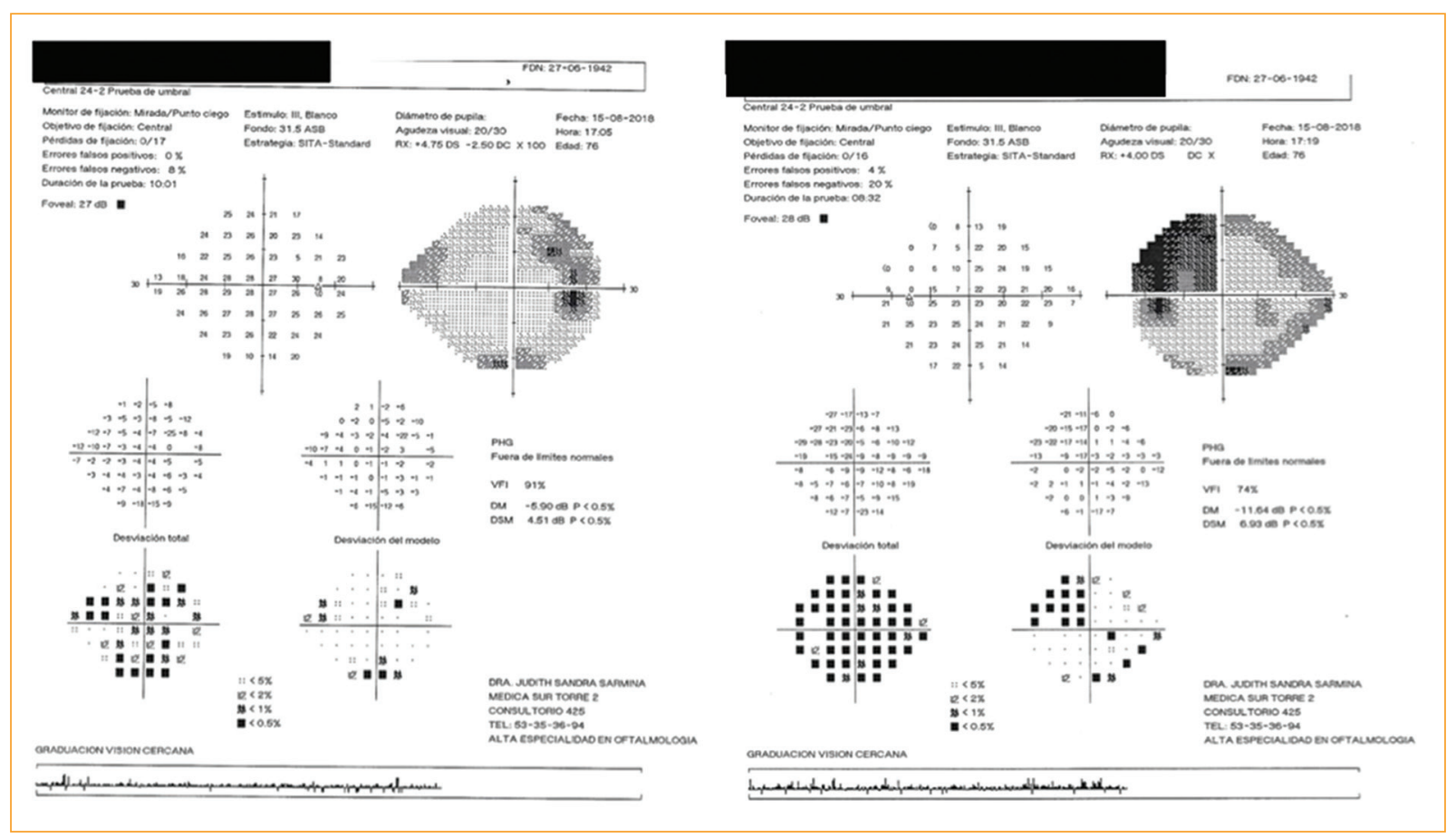

Figure 2. 24-2 SITA Standard Automated Perimetry. Right eye with a slight blind spot enlargement and upper nasal step increase. Left eye with blind spot enlargement and a superior arcuate scotoma.

before the age of $50^{-3,4}$. The diagnosis of plateau iris should be considered when there is a persistently narrow angle even with patent iridotomies. However, it should not be excluded if after the iridotomy the angle is partially opened, since it may be an incomplete plateau iris syndrome, as in the case of our patient, which seemed not to behave like a classic plateau iris, both by the age of presentation as well as by evolution. Close clinical follow-up and regular gonioscopic evaluation help to identify this rare condition, which is a real diagnostic and treatment challenge.
The possibility of plateau iris-like configuration caused by cysts in the root of the iris and ciliary body, or ciliary body tumors, which can generate a plateau iris configuration with consequent angular closure, should be suspected within the differential diagnoses. Although the most common finding is a single cyst, in up to a third of cases these can be multiple. When the cysts affect an area greater than $180^{\circ}$ of the iris, which occurs in $10 \%$ of patients, angle-closure glaucoma can develop ${ }^{6}$.

It is important to mention that the definitive diagnosis of plateau iris is obtained by UBM that shows its classic 


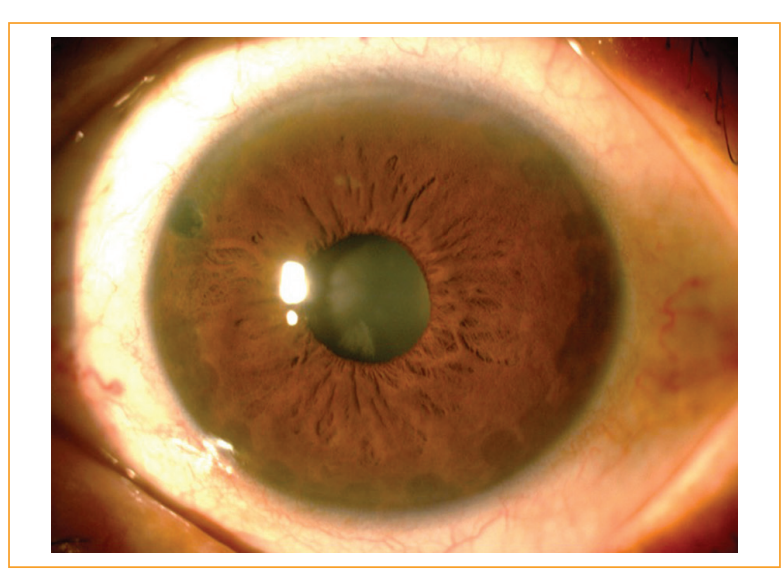

Figure 3. Left eye four weeks after argon laser peripheral iridoplasty.

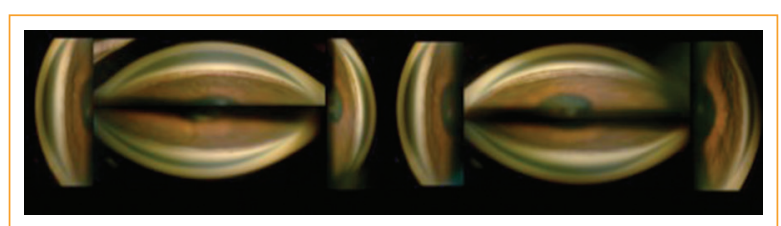

Figure 4. Gonioscopy of both eyes with open angles after argon laser peripheral iridoplasty.

characteristics such as the absence of ciliary sulcus and the presence of anteriorly situated ciliary processes that push the periphery of the iris and the presence of a double hump $p^{1,2}$. Likewise, UBM allows evaluating the anteroposterior axis of the lens that when enlarged, can push the root of the iris anteriorly and cause an angular closure. In our patient we did not find this characteristic, since her anteroposterior axis was within normal parameters $(3-6 \mathrm{~mm})$ : the right eye with 4.17 $\mathrm{mm}$ and the left eye with $4.37 \mathrm{~mm}^{7}$. Also, our patient did not have a lens opacity dense enough to consider cataract surgery. The removal of a clear lens in cases of plateau iris is a subject of great controversy due to the inherent risks of cataract surgery.

Argon laser peripheral iridoplasty is the treatment of choice, useful as long as there is no lens-induced angle closure $^{3,6}$.

\section{Conclusions}

The case presented is relevant because the low incidence ( $10 \%$ of angle-closure glaucomas) of plateau iris can lead to underdiagnosis, since it is frequently excluded in cases of patent iridotomy with angle changes and a decrease in IOP. The patient was outside the age range for plateau iris, probably because she was asymptomatic. It is important to evaluate by UBM the possibility of plateau iris in patients with primary angle-closure and correlate it with the clinical presentation.

\section{Conflicts of interest}

The authors declare no conflicts of interest.

\section{Ethical disclosures}

Protection of human and animal subjects. The authors declare that no experiments were performed on humans or animals for this study.

Confidentiality of data. The authors declare that they have followed the protocols of their work center on the publication of patient data.

Right to privacy and informed consent. The authors have obtained the written informed consent of the patients or subjects mentioned in the article. The corresponding author is in possession of this document.

\section{References}

1. Cronemberge S. La importancia de la biomicroscopía ultrasónica en el diagnóstico de la configuración del iris en meseta. Vision Pan-America. 2014;13:101-5.

2. Mansoori T, Sarvepally VK, Balakrishna N. Plateau iris in primary angle closure glaucoma: an ultrasound biomicroscopy study. J Glaucoma. 2016;25:82-6.

3. Stefan C, Iliescu DA, Batras M, Timaru CM, De Simone A. Plateau iris — diagnosis and treatment. Rom J Ophthalmol. 2015;59:14-8.

4. Feraru $\mathrm{Cl}$, Pantalon $\mathrm{AD}$, Chiselita $\mathrm{D}$, Branisteanu D. Plateau iris syndrome - case series. Rom J Ophthalmol. 2015;59:188-93.

5. Fernandéz Argones L, Piloto Díaz I, Díaz Águila Y, Obret Mendive I, Ferrer Guerra MT, Álvarez Cisneros G. Consideraciones terapéuticas en el cierre angular primario. Rev Cubana Oftalmol. 2012;25:427-32.

6. Ispa-Callén MC, Lara-Medina J, Zarco-Tejada JM, López-Mondéjar E, Celis-Sánchez J, González-Del-Valle F. Argon laser iridoplasty as treatment of plateau like iris configuration secondary to multiple ciliary body cysts: long-term follow-up by ultrasound biomicroscop. Arch Soc Esp Oftalmol. 2009;84:569-72.

7. American Academy of Ophthalmology. Fundamentals and principles of ophthalmology. 2011-2012; Chapter 2 Lens:67. 